\title{
Futuro e história: análise da temporalidade atual ${ }^{*}$
}

\author{
The future and history: analysis of contemporary temporality
}

\author{
Gisele Iecker de Almeida \\ gisele.ieckerdealmeida@ugent.be \\ Doutoranda \\ Universiteit Gent \\ Sint-Pietersnieuwstraat 35, UFO \\ 9000 - Gent \\ Belgium
}

\section{Resumo}

Ao final do século $X X$, a segurança da humanidade na unidade e direção do conhecimento foi abalada. Nesse contexto, desde 1970, a escrita da história se encontra em um momento crítico, e é evidente que, desde então, a historiografia vem perdendo terreno na sociedade. O "presentismo", efeito do colapso da ideia de futuro e da concepção linear e progressiva do tempo, exige uma nova abordagem do passado histórico e requer uma produção de conhecimento relevante para a contemporaneidade. Informados pela filosofia e pela teoria da história contemporâneas, procuramos investigar qual poderia ser o papel desempenhado pela historiografia nesta estrutura emergente da temporalidade. Nesta proposta, o historiador passa a entender-se como um mediador da nossa relação com os eventos passados, formando uma ponte entre passado, presente e futuro.

\section{Palavras-chave}

Temporalidades; Futuro; Historiografia.

\begin{abstract}
At the late twentieth century, humanity's assurance of the unity and direction of knowledge was shaken. In this context, since the 1970s the writing of history has been in a crucial moment and it is noticeable that historiography has been losing ground in society. "Presentism", an effect of the collapse of the idea of a future and of the concept of linear and progressive time, involves a new approach to the historical past and requires a production of knowledge that is more relevant to the present-day. Informed by the contemporary philosophy and theory of history, we set out to investigate what role could be played by historiography in this emerging structure of temporality. In this proposal, historians see themselves as mediators of our relation to past events, thus bridging the past, the present and the future.
\end{abstract}

Keywords

Temporalities; Future; Historiography.

Recebido em: 13/2/2014

Aprovado em: 14/4/2014

* Esta pesquisa conta com o financiamento da Coordenação de Aperfeiçoamento de Pessoal de Nível Superior (CAPES). 
Vivemos um momento histórico no qual as crises são múltiplas. Esta análise estuda três de suas vertentes que aparentam ser de particular importância para o conhecimento do passado. Primeiro, a virada linguística, que afirma que a verdade - tão cara aos historiadores - não pode ser a referência definitiva, uma vez que se encontra sempre na estrutura da linguagem. Em segundo lugar, após 1989, fomos testemunhas do processo de formação de um novo regime de historicidade: de acordo com autores como François Hartog e Andreas Huyssen, passamos de uma compreensão moderna do mundo (baseada na ideia de progresso) a uma historicidade que pode ser concebida como um "presente eterno", onde passado e futuro são continuamente recriados pelo presente. E, finalmente, a terceira crise, que ocorre na própria ideia do futuro: as crises políticas, econômicas, ecológicas e outras que ocorrem simultaneamente impedem a concepção de alternativas, ao mesmo tempo em que a ideologia neoliberal afirma que "não existe alternativa".

Se realmente estamos em meio a uma crise de compreensão do passado, este seria um bom momento para refletir sobre a interpretação historiográfica, em um diálogo aberto com a filosofia política, a ética e a filosofia da história. Em uma tentativa de lançar luz sobre os problemas historiográficos deste momento, especialmente os relacionados com a perda de interesse sobre o passado na sociedade contemporânea, procuramos realizar esse diálogo no contexto da filosofia da história e da teoria historiográfica atuais.

Superar a crise atual exige uma nova reflexão teórica, bem como uma nova concepção do ser histórico. Para isso, a própria disciplina histórica deve necessariamente passar por uma transformação, algo que não é de todo negativo. É nesse contexto que o presente artigo procura responder à pergunta: "que tipo de disciplina histórica nos interessa?".

Este ensaio procura indicar possíveis reflexões na resposta a essa ampla questão e abrir caminhos para o longo percurso que nos resta por diante. Acreditamos ser importante começar com o entendimento do conceito de tempo na história, ou melhor, dos "tempos" da história, usando o termo cunhado por Agnes Heller. Uma ênfase especial foi conferida ao presente, por ser o momento da criação da historiografia - que, por sua vez, como veremos, pode ser entendida como a criação de uma imagem do passado.

Essa compreensão do trabalho do historiador expõe a curiosa capacidade para não só construir, mas também alterar imagens do passado, na medida em que evoca uma preocupação sobre o uso da história - uma preocupação pouco comum em departamentos acadêmicos, mas central para a busca de uma historiografia relevante para a sociedade contemporânea.

Se nossa intenção é analisar e adaptar a historiografia às necessidades atuais, fazendo um balanço não de todo diferente daquele proposto por Friedrich Nietzsche na II Consideração Intempestiva, é importante ponderar sobre o entendimento contemporâneo de tempo: sem dúvida, a agilidade da reprodução de informações e a velocidade do progresso técnico mudaram o entendimento 
de presente, passado e futuro, e não podemos afirmar com certeza que esse processo haja concluído e que já possuamos uma imagem clara da estrutura emergente da temporalidade.

Uma possível conclusão das notas a seguir seria a de que o historiador, como especialista em mudanças ao longo do tempo, tem a capacidade - e talvez a responsabilidade histórica - de atuar como mediador do ontem, hoje e amanhã, buscando auxiliar na abertura de alternativas futuras.

\section{Os tempos da história}

O tempo não para. O presente está constantemente se tornando passado, em um fluxo constante de "agoras" em direção a "futuros" em aberto. Isso implica que cada evento ocupa certa duração, sempre presente: nada acontece fora de um presente que passa. Assim se revela que habitamos o tempo mais curto, ponto de encontro entre passado e futuro infinitos. O presente, que ocorre constantemente, este instante que substitui outros instantes e que é feito de acontecimentos, é tido como o momento da ação.

Isso não poderia ser diferente, pois o presente detém certa superioridade ontológica: é o único momento que possui uma existência objetiva, é o único lugar que realmente existe - estamos sempre nele. Tanto é assim que ele abrange outras formas de tempo. Em outras palavras, passado e futuro possuem uma assimetria radical em relação ao presente, uma vez que só podem surgir de uma leitura de um presente que imagina e traça planos para o futuro, relembra e investiga o passado, etc. O intervalo entre passado e futuro, fratura no meio do tempo, é o ponto em que se unem a experiência do passado e a expectativa do futuro que se antecipa.

Arthur Danto fornece-nos uma imagem da incongruência entre passado e presente: "imagine o passado como um grande recipiente, um cubo, onde são organizados na mesma ordem em que aconteceram, todos os eventos já ocorridos" (DANTO 1965, p. 146). ${ }^{1}$ Tal recipiente se estiraria a cada instante, abrindo espaço para que continuem entrando todos os fatos à medida que forem ocorrendo. $O$ presente pode, assim, ser considerado a "borda crescente ao longo do passado" e que dele se distancia exatamente ao ritmo do fluir do tempo (ver Figura 1). Ambos se movem em conjunto, um alimenta o outro. As ocorrências presentes vão rapidamente encontrando seu caminho no grande depósito da história.

A imagem de Danto ("história-recipiente") é interessante por sublinhar a sempre presente adesão de diferentes estratos do tempo, enfatizando o caráter presencial do passado no momento presente. No esquema, fica claro que o passado não tem a capacidade de se automodificar: o presente é o único momento em que mudanças podem ocorrer. Uma vez adentrado o recipiente, tudo o que pode acontecer a um evento passado é a (constante) expansão de sua distância em relação ao presente e a adição de correlações e eventos contemporâneos, as "descobertas historiográficas". 

O recipiente
vai se tornando
mais profundo
ao longo do
tempo

Figura 1

PRESENTE

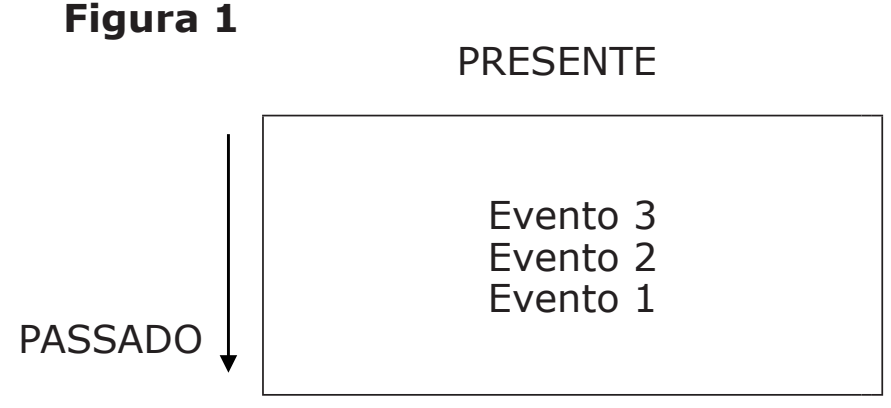

Portanto, os que se debruçam sobre o passado para responder algumas perguntas atuam como aquele que anda pelos corredores de um enorme guarda-volumes. Ali se podem encontrar alguns artefatos interessantes e outros curiosos. É possível tocar e ver a utilidade de cada um, para, finalmente, retirar o que serve e que se veio buscar. Todos aqueles que andam pelas galerias da história escrutinam o passado: suas relíquias, devidamente organizadas e catalogadas, estão disponíveis a todos (OAKESHOTT 1983, p. 13). São "emprestadas" quando forem úteis ao presente, para uma variedade de atores. Os membros da classe política podem dali retirar citações esquecidas; escritores, informações e inspiração; e a maioria de nós passa por ali em busca de um exemplo, modelo ou lição.

Nessa abordagem, os historiadores seriam responsáveis pela organização e manutenção das galerias. São os que classificam, nomeiam e enumeram os itens listados e, quando um novo item é adicionado à coleção, decidem em qual corredor deve ser armazenado. Além disso, o especialista dedicado a investigar o passado, o produtor do discurso histórico em geral e, certamente, também o professor universitário especializado em determinado momento do passado trabalham a partir do momento presente.

Mas não nos enganemos: a metáfora do passado como um recipiente ou galeria pode dar a impressão de que o passado "está" em algum lugar e de que é de um recipiente universal neutro que se trata. Nada poderia ser mais diferente. O passado, por definição, não está presente: é uma construção - de historiadores, sociedades - criada a partir de objetos residuais que sobreviveram e que estão agora disponíveis para ser ouvidos e consultados (OAKESHOTT 1983, p. 16) e transmitida através de livros de história. Encontra-se no momento presente, que dificilmente poderia ser considerado um recipiente neutro.

\section{A consciência histórica}

Olhando mais de perto a situação temporal da consciência histórica, seria possível pensar em uma pluralidade do tempo? Diferentes presentes, historicidades e formas de compreender sua passagem? Agnes Heller afirma que sim, pois seria possível falar de uma confluência de nove instâncias temporais diferentes (ver Figura 2): 


\section{Figura 2}

História presente
(fluxo constante de
eventos)
História futura
História passada
(não representa
uma alternativa:
simplesmente a
explicamos)

Presente histórico (construção do presente)

Futuro histórico (futuro de um presente passado)

Passado histórico (o "antigo", ao qual somos alheios)
Época presente (símbolos e valores que são significativos: onde estamos)

Época presente futura

Época presente passada (passado histórico compreendido pelo presente)

Vivemos, de fato, em três presentes (e distinguimos três passados e três futuros). Isso não quer dizer que todos os seres vivem ao mesmo tempo em três presentes, mas sim que do presente em que vivemos se desprendem todos os três. Assim construímos o futuro (HELLER 1984, p. 47).

Para a pensadora húngara, um passado que não tenha uma "presença presente" (traços, memórias, referências) é um passado que não pertence ao tempo presente, ou seja, é uma história passada. Ou bem não o conhecemos, ou não nos importa, ou não o tocamos mesmo que o tenhamos à disposição. Esses são os eventos passados cujas consequências não representam uma alternativa para o atual, não nos ameaçam ou dão esperança; são os que puramente explicamos.

Essa relação com o passado pode ser alterada. Tudo depende da seleção historiográfica (TRAVERSO 2006, p. 71), que dá reconhecimento ao passado. A partir do momento em que usamos um evento passado, incluímo-lo em um discurso histórico que o atualiza, chegando a nossa realidade e nossa contemporaneidade; assim, esse fato se faz presente e real. Em termos hellerianos, ele é relevante para o presente, passou a participar do "presente histórico" que compõe o "tempo presente", caracterizado como "estrutura cultural dentro da qual nos encontramos [...] era cujos símbolos e valores se fizeram significativos a nós" (HELLER 1984, p. 47). ${ }^{2}$ Faz parte da função do historiador escolher, dentre todo o passado da humanidade, quais são os fatos relevantes para compreender e agir no presente, aqueles que vemos como a fonte de nossas crenças, conhecimentos e formas de ser no mundo.

A época atual seria, portanto, caracterizada pela "soma total de objetivações significativas, sistemas e valores essenciais para o nosso modo de vida, que 'dirigem' e 'conduzem' nossas atitudes para com o mundo' (HELLER 1984, p. $48),{ }^{3}$ todas presentes na atualidade, quer como ausências ou continuidades (o

\footnotetext{
${ }^{2}$ No original: "[...] estructura cultural en cuyo interior nos encontramos [...] época cuyos símbolos y valores se han hecho significativos para nosotros".

3 No original: "[...] suma total de las objetivaciones significativas, los sistemas de creencias y los valores esenciales a nuestro sistema de vida, que "dirigen" y "conducen" nuestras actitudes frente al mundo".
} 
que era e já não é/o que resta), ou melhor, como ameaças ou esperanças sobre o futuro (KOSELLECK 2001, p. 118).

É imaginando e recriando eras presentes passadas que a história se mostra feita de coincidências e esforços coletivos. Essa metodologia proporciona uma relação dialógica entre presente, passado e futuro, favorecendo a incorporação de diferentes historicidades na projeção de um futuro melhor. Nesse sentido, Heller diz sem rodeios: "A 'responsabilidade global' nos compromete na reconstrução do passado como épocas presente-passadas" (HELLER 1984, p. 50). ${ }^{4}$

O que sugere Heller é que observemos o passado como momentos presentes passados prenhes de esperança para um futuro que pôde ter sido executado pela metade, cheio de circunstâncias imprevisíveis que possuem um impacto no desenvolvimento do presente, como acontece em nossa contemporaneidade: "Saber que os homens do passado possuíam expectativas, desejos, medos e projetos traz consigo a quebra do determinismo histórico, ao reintroduzir retrospectivamente a contingência na história" (RICOEUR 1999, p. 50). ${ }^{5}$

De uma vez, entendemos a relação de continuidade/descontinuidade, mudança/duração que afeta todo o passado. O que persiste é aquilo que se manteve desde o passado até o momento presente. As mudanças são a transição do futuro passado (de civilizações anteriores, por exemplo) até nosso passado presente.

Esse entendimento nos liberta para pensarmos mais claramente a relação entre os tempos e sua confluência, que faz e desdobra o "agora"; permite-nos lançar um olhar para o futuro que o projeta, como decadência ou utopia, ou talvez até mesmo como um possível desaparecimento de todo presente histórico. Essa abordagem garante a existência de muitos amanhãs possíveis. Nesse contexto, a historiografia encontra razões para luzir no presente.

O presente necessita ser totalmente implantado e fazer-se passado, revelando suas consequências, para que o possamos entender. Por sua vez, para ser compreendido, o passado tem a necessidade de convergir para o presente e, portanto, com a leitura presente do passado (historiografia), marcada pelos traumas de sua época presente. Um relato histórico exilado de seu tempo é um peso morto, uma "história obituária" que não acrescenta nada de útil ao homem (NIETZSCHE 1980).

Ao inclinar-se sobre o passado, o investigador tem preocupações de seu tempo (econômicas, políticas, sociais, familiares), e isso se reflete em seu pensamento e escolha ao (re)escrever uma história. Seus desejos, medos, expectativas e experiências, suas esperanças utópicas e ceticismo têm o seu lugar na seleção do tema a ser trabalhado (RICOEUR 1999, p. 60; JENKINS 1991). Aponta Ricoeur (1999, p. 93): "Essa relação com o presente e o futuro,

\footnotetext{
${ }^{4}$ No original: "La 'responsabilidad planetaria' nos compromete en la reconstrucción del pasado en cuanto épocas presente-pasadas".

${ }^{5}$ No original: "Saber que los hombres del pasado tenían expectativas - previsiones, deseos, miedos y proyectos trae consigo la quiebra del determinismo histórico, al reintroducir retrospectivamente la contingencia en la historia".
} 
inevitavelmente, influencia a escolha de seu objeto de estudo, os problemas que coloca e o peso dos argumentos em suas explicações e interpretações". ${ }^{6}$

No entanto, os historiadores acreditaram-se capazes de olhar para o passado objetivamente, à procura de nada mais do que "o passado por si mesmo". Segundo essa concepção, a pesquisa histórica seria como um bilhete de ida e volta, uma viagem a um país distante (LOWENTHAL 1985). O historiador, um ser estranho que está em algum lugar entre os dois mundos, levaria do presente em que vive, em sua bagagem, as categorias de análise a ser utilizadas. É como se mergulhasse no passado: observa e toma notas, sem tocar em nada, e, ao "retornar" ao presente, escreve suas descobertas. O principal objetivo seria produzir uma réplica exata do passado, de acordo com os preceitos em voga desde o final do século XIX.

Hoje, os filósofos da história já não negam o carácter intencional da disciplina. Uma possível caracterização para compreender a história atual diria que o passado seria como uma zona de obras (JENKINS 1991): o historiador é quem escolhe a história a ser narrada (recorte temporal, perspectiva, personalidades, etc.) e quais categorias descritivas serão usadas na construção dessa história.

Nessa compreensão da disciplina, voltamo-nos ao passado para entender algo do presente: queremos saber se estamos à altura do passado, podemos medir nossas capacidades com o anteriormente alcançado. "Olhamos para o passado, porque queremos vê-lo em relação ao reflexo de quem somos" (OAKESHOTT 1983, p. 15). ${ }^{7}$

O presente determina que passado buscamos e que perguntas Ihe fazemos. Uma história que construa referencialidade, usando o pensamento figurativo, argumentação, teoria, conceitos e ética, seria uma história capaz de facilitar a reabertura do futuro. Essa disciplina nos daria a possibilidade de pensar uma pesquisa histórica que questione a própria historicidade humana, abrindo a imaginação presente a possíveis futuros a partir do estudo do passado e suas experiências e expectativas em relação ao seu presente e futuro (dado ou não).

A história hoje se reconhece cada vez mais como um conhecimento contingente, constantemente reescrito e reestruturado à luz do presente. Essa característica inegável é o que torna possível para outro momento histórico que eventos passados (teorias, costumes...) possam tornar-se inaceitáveis, ou seja, que um evento anteriormente considerado normal passe a ser considerado uma vergonha, como o uso da violência na educação, em voga até meados do século passado. Nossa visão do passado é formada a partir do momento presente e, certamente, temos de trabalhar na (in)segurança de que a contingência do presente estará conosco no futuro.

A constante reescrita e releitura do passado destaca a plasticidade do que aconteceu e que, ao permitir modificar-se e recontar-se de várias maneiras,

\footnotetext{
${ }^{6}$ No original: "Esa relación con el presente y con el futuro influye inevitablemente en la elección de su objeto de estudio, en los problemas que plantea, en sus hipótesis y en el peso de los argumentos que recorren sus explicaciones y sus interpretaciones [...]."

7 No original: "[...] we are concerned with what happened on respect of its reflection in what we are".
} 
em uma eterna construção retrospectiva do discurso histórico, se multiplica. "A história," no singular, terminou. Temos histórias, tantas quanto o número de autores dispostos a contá-las (WHITE 1993, p. 331). Essas histórias são oferecidas para os mais diversos usos: governos totalitários mantiveram escritórios dedicados a essa empresa, editando fotos, textos e arte para que se encaixassem com a narrativa que buscavam manter. A "americanização do Holocausto", uma releitura fortemente mediada e popularizada, está em uso até os dias atuais (TRAVERSO 2006). Grande parte da historiografia realizada até os dias de hoje poderia ser classificada como um esforço de "manutenção do que existe". Por sua maleabilidade, a história exige cuidados constantes.

\section{O peso do presente}

A partir das últimas décadas do século $X X$, os historiadores voltam a questionar a aspiração de fazer da história um conhecimento objetivo e a discutir a fronteira epistemológica entre história, arte e ciência. Desde então é comum encontrar no campo da teoria da história textos que discutem o "mal-estar da história", "revoluções na historiografia", "crise historiográfica", "novos paradigmas", "fim da história", enfim, a chegada da virada linguística para o campo que alguns afirmam ser o mais conservador de todos.

O annalista Roger Chartier resume a questão afirmando que a virada linguística reforçou a constatação de que (1) a língua é um sistema de signos que geram significados múltiplos e instáveis, fora de qualquer intenção ou controle subjetivo, e (2) a realidade não é uma referência objetiva, externa ao discurso, mas é sempre construída em e através da linguagem (CHARTIER 2007). A realidade primária que poderia servir de referência é inacessível: só temos acesso ao mundo por meio de estruturas criadas e manipuladas pelo homem, sempre formatadas de acordo com os preceitos do momento de sua criação.

Do mesmo modo como não podemos acessar a realidade, também não podemos acessar o passado para verificar o nível de precisão das histórias que escrevemos. Essa "nova estrutura" que a "virada" nos oferece convida-nos a ver a história como uma representação engendrada pelos próprios historiadores, evidenciando a natureza intencional e invariavelmente textual da historiografia (ANKERSMIT 2001). O passado não está em nenhuma parte, apenas em nosso discurso sobre ele.

A crescente fragmentação da disciplina - que é visível na multiplicidade de técnicas narrativas aplicadas, objetos, problemas, perspectivas... - está ligada ao debate mais amplo sobre a subjetividade do historiador e a relatividade da verdade na escrita historiográfica, gerando o questionamento de sua funcionalidade e a proposição de profundas mudanças no campo da história.

Entre historiadores mais dogmáticos, esses fatores tendem a gerar muita preocupação com o futuro da disciplina. O desprezo da maioria dos historiadores pela teoria é notável, e, se acrescentarmos a isso a rejeição de muitas das propostas feitas pela "virada", obteremos o seguinte resultado: analisando publicações contemporâneas no campo da historiografia, observaremos mais facilmente o volume de trabalhos realizados no formato "pré-1990". 
Mesmo assim, muitos afirmam que a investigação do passado já não pode ser entendida como era há algumas décadas. O historiador tem de enfrentar alguns desafios que Ihe foram impostos pela filosofia após a virada narrativa da teoria. Essa mudança de perspectiva mostra que as condições textuais governam todo o trabalho historiográfico e, consequentemente, a produção de todo o conhecimento histórico.

O passado não está disponível para que possamos contrastar as versões e determinar quem conta a história mais "verdadeira": tudo o que temos são outras histórias, outros historiadores, de outras épocas. Ankersmit afirma que essa é a prova de que o passado não tem nada a dizer quando se trata de história. A ideia em jogo aqui é a de que a história (Rerum Gestarum) é muito mais ampla do que o passado (Res Gestae), já que as diferentes perspectivas, releituras e análises da disciplina histórica não necessariamente pertencem ao pretérito. "[...] o texto histórico é um árbitro com muitos mais recursos sobre o passado e nós mesmos do que jamais havíamos considerado possível" (ANKERSMIT 2012b). No fim das contas, quantos habitantes da antiga Atenas reconheceriam sua polis nas descrições historiográficas em que hoje nos baseamos para conhecê-la?

Gostaria de destacar algumas características comuns aos pensadores que aceitaram os desafios linguísticos no campo da história. A visão compartilhada por esses leitores de Nietzsche é que a disciplina é um discurso sobre o passado, que, por sua vez, só é acessível hoje por meio de textos. Assim, a história perde suas máscaras de legitimação - objetividade, verdade, cientificidade... - e passa a ser entendida como uma rede discursiva, uma construção social, altamente dependente dos preceitos e opiniões dos historiadores, seus intérpretes.

Há uma aceitação generalizada de que a palavra não esgota a questão: podemos falar muito mais do que é ou foi (ou seja, do que houve). Essa visão se faz palpável no comentário de Ankersmit sobre a capacidade dos historiadores de dizer mais do que a relíquia histórica ou o próprio passado comportam. Há sempre algo a acrescentar, e, no final, há sempre a possibilidade de adicionar uma vírgula e continuar a análise histórica, mudando a perspectiva, fazendo um paralelo com outras épocas, construindo pontes com o presente e gerando novos significados a partir do já ocorrido.

A história é aqui entendida como uma forma de invenção de categorias e significados. O historiador-intérprete é o agente que transforma o passado em história, em um discurso narrativo que em muitos casos se assemelha à literatura. Nas palavras de White: "[...] a maioria da historiografia é a tentativa de impor uma forma significativa a um passado sem sentido" (WHITE apud JENKINS 1995, p. 148). ${ }^{8}$ A história passa a ser vista como um conhecimento responsável por ordenar o caos do passado, com a capacidade de oferecer uma visão libertadora para o futuro. 


\section{A utilização da história}

Havendo analisado o estado atual da produção e da teoria do conhecimento historiográfico, cabe-nos dar um passo adiante na compreensão desse campo examinando o que realmente faz um historiador ao transformar o passado em história. Seguiremos os três passos indicados por Tzvetan Todorov como essencialmente historiográficos, necessários para fazer reviver o passado no presente. O primeiro passo necessário para a composição do discurso histórico, o estabelecimento dos fatos, consiste em uma seleção do passado a ser investigado, a identificação de um problema para o qual se buscará contribuir para as discussões historiográficas do presente. "[...] De todos os vestígios deixados pelo passado, decidimos reter e preservar apenas alguns, considerando-os, por um motivo ou outro, dignos de ser perpetuados" (TODOROV 2002, p. 147). ${ }^{9}$

A escolha do tema a ser pesquisado implica necessariamente um recorte (geralmente temático, temporal e geográfico) e um reconhecimento dos eventos a serem narrados, bem como a identificação dos personagens que terão uma voz na narrativa resultante. Essa primeira etapa é, literalmente, uma hierarquização dos eventos passados em ordem de relevância. E - como comenta Ankersmit - baseia-se essencialmente em textos de pesquisadores que examinaram a questão anteriormente.

A segunda fase do trabalho de apropriação do passado é a interpretação dos eventos, que inclui a forma como a história será contada: a narrativa dos acontecimentos, incluindo a seleção de uma perspectiva narrativa, a descrição das estruturas que "conectam" os fatos, o desenvolvimento de uma determinada classificação e terminologia e a criação de significado - as substâncias narrativas, para continuar com a linguagem ankersmitiana. "A construção de sentido tem como objetivo compreender o passado" (TODOROV 2002, p. 149). ${ }^{10}$ Os fios condutores desenvolvidos nesta fase funcionam como pontes que levam a outras cronologias históricas, áreas do conhecimento, etc. A construção de sentido está sempre intrinsecamente ligada ao recorte anteriormente realizado.

A etapa final - a instrumentalização da história - é posterior ao trabalho do historiador. Uma vez decidido o recorte e dada uma coerência à explicação dos eventos em uma narrativa, a história-escrita se faz disponível ao uso social e político. Apesar de estar claramente fora do seu controle, o uso da história também é uma espécie de orientação geral do trabalho historiográfico, pois está diretamente relacionado àquilo que quer explicar ou apresentar ao mundo o historiador e a suas razões para fazê-lo.

Sabemos que a história é intencional e que o historiador se volta para o passado com um plano, algo que quer fazer: seja para reformular e desafiar a versão atual do ocorrido, aprender lições e traçar paralelos com problemas semelhantes em outros períodos, ou legitimar instituições de sua época presente, a história sempre se coloca a serviço de alguma causa (Cf. WHITE 1993; JENKINS 1991).

\footnotetext{
${ }_{9}^{9}$ No original: "[...] de todos los rastros dejados por el pasado, decidiremos retener y consignar sólo algunos, considerándolos, por una razón u otra, dignos de ser perpetuados."

10 No original: "La construcción del sentido tiene como objetivo comprender el pasado".
} 
Os historiadores geralmente não se veem como agentes sociais (TODOROV 2002, p. 154; ZINN 1990, p. 1), o que equivale a dizer que não estão acostumados a ponderar sobre o uso posterior, para além da academia, de suas obras. No entanto, quando a história é ou se faz relevante para o presente, utilizam em seus trabalhos argumentos racionais para explicar ações, metas, tentativas e atitudes que proporcionam munição para um ou outro grupo na sociedade.

$\mathrm{Na}$ verdade, os historiadores são sempre guiados por seus valores pessoais, parte do quadro temporal que é parte integrante da nossa existência. "Quanto mais importante a história - mais significativa -, mais ela envolve o nosso 'agora' e nossa comunhão e mais seletivamente a contamos" (HELLER 1984, p. 56). ${ }^{11}$

Durante o século $X X$, a história tem sido acusada de "contaminar" alunos por explicar e racionalizar fatos brutais. Podemos explicar o incompreensível? Nomear e classificar já são uma forma de entendimento. Encontrar causas e efeitos de eventos passados e determinar a motivação dos atores não é só explicar, mas também justificá-los. Dado o potencial para o abuso do passado sob o "controle da memória" ou para a instrumentalização abusiva da história por certos grupos ou governos, a história-conhecimento desempenha o importante papel de mediação e verificação de informações. É importante que se tenha consciência desse papel e que ele seja desempenhado de forma responsável.

O peso e o impacto dos acontecimentos históricos não são fixos e imutáveis. "Pelo contrário, evoluem, se consolidam ou enfraquecem e permanentemente contribuem para redefinir o estatuto da memória" (TRAVERSO 2006, p. 71). ${ }^{12}$ Se trabalharmos com a ideia de que o passado é sempre uma interpretação ou representação em constante reconstrução, teremos de admitir que o peso simbólico de eventos e ações em tempos passados pode mudar.

\section{Futuro e história}

Confinar o ocorrido estritamente ao passado é de alguma forma inutilizá-lo: o passado se põe a serviço do presente ao ser resgatado e colocado em uso. A história, ao selecionar e recortar aquilo que nos pertence, isto é, aqueles símbolos e valores que compõem o presente, tem tanto o poder de nos liberar como o de nos atar. Isso quer dizer que a história não é necessariamente boa (TODOROV 2002). É gerando significado histórico que o historiador insere novos conteúdos às discussões presentes: historiográficas, políticas, legais, científicas e sociais. Seu recorte é o que separa o "real", o histórico, do a-histórico e irreal, o utópico (WHITE 2007). E são os motivos e valores que mobiliza para escrever a história, juntamente com a posterior utilização dessa história, que conferem seu peso ao momento presente.

Ankersmit ilustra a importante característica da historiografia de gerar significado histórico com a seguinte análise (de Danto) sobre uma estátua de Napoleão:

\footnotetext{
${ }_{11}$ No original: "Cuanto más importante la historia - más significativa - más involucra a nuestro 'ahora' y a nuestra comunión y más selectivamente la contamos".

12 No original: "Al contrari, evolucionen, es consoliden o s'aflebeixen, i contribueixen permanentment a redefinir l'estatut de la memòria".
} 
Quando Napoleão é representado como um imperador romano, o escultor [Canova] não está apenas representando Napoleão, em uma pose antiquada e em roupas que acredita terem sido usadas pelos imperadores romanos. Pelo contrário, o escultor anseia que o espectador tome, com relação ao seu sujeito - Napoleão - as atitudes adequadas aos maiores imperadores romanos - César ou Augusto (DANTO apud ANKERSMIT 2012a).

Danto reflete sobre a relação arte/criação de sentido, mas essa ideia pode ser equiparada à historiografia - e isso interessa ao pensador holandês, que assim esclarece sua teoria da história, traçando um paralelo entre metáfora e representação. Ankersmit sugere que a história tem o poder de caracterizar uma representação como algo, da mesma forma que o escultor representa Napoleão como um imperador romano.

As criações de historiadores (o conceito de Renascimento, por exemplo) nos convidam a ver um período histórico com tudo o que associamos a ele. Essa singularização é o que Paul Ricoeur chamou de uma identificação forte, uma representação do passado "[...] que muitas vezes é laudatória e reivindica sua lembrança e ritualização" (RICOEUR 1999, p. 47). ${ }^{13}$ Em outras palavras, a história representa o passado, criando significados que necessariamente exigirão que o leitor tome certa atitude em relação a certos fatos, sujeitos ou conceitos. "A memória não é apenas responsável por nossas crenças, mas também por nossos sentimentos" (TODOROV 2000, p. 26). ${ }^{14}$ Nessa curiosa capacidade de moldar e mudar a imagem do passado reside a importância da historiografia para o presente.

Compreender a história como formadora de conceitos sobre o passado, um conhecimento que, por sua vez, funda o presente e possibilita novas abordagens em relação ao futuro, revela a relação intrínseca entre história e ideologia. Não seria demasiado explicitá-lo mais uma vez: todo discurso histórico é contingente, subjetivo e parcial. Busca promover uma visão, sempre para um grupo social (sempre está a serviço de uma causa). Também a historiografia contemporânea, que retrata sua contemporaneidade como uma consequência imediata do passado, encontra-se a serviço de algo - a ideologia dominante no presente -, criando a impressão de que o presente é inevitável ("sempre foi assim", "é o que é") e que "não pode ser modificado", naturalizando, dessa forma, a história e a realidade do tempo presente.

O historiador que aceitar entrar nesse jogo de criação de sentido ao interpretar o passado, deverá fazê-lo ciente de suas regras, sua responsabilidade e possíveis resultados, além de ter claro o uso que pode ser dado à representação do passado que propõe. Deve olhar para o passado, com o qual cria sua análise, com o olhar fixo no presente em que se encontra e no futuro, quando sua história estará disponível para a sociedade. O que indicamos é talvez uma possível mudança de rumo para a historiografia: que deixe de colocar a ênfase no passado para colocá-la no futuro.

\footnotetext{
${ }^{13}$ No original: "[...] que frecuentemente es laudatoria y reclama su conmemoración y ritualización". 14 No original: "La memoria no es sólo responsable de nuestras convicciones sino también de nuestros sentimientos".
} 


\section{Restaurar a esperança}

Uma crítica comum aos historiadores está relacionada à falta de reflexão teórica sobre a disciplina (DADDOW 2005). Heidegger foi um dos que expressaram tal desaprovação, alegando que os historiadores se recusam a perguntar-se rigorosamente por que fazem o que fazem,

conspirando coletivamente $[\ldots]$, fingindo ser justificável para os historiadores "profissionais" receber para desfrutar de um antiquarianismo autoindulgente ou das intrigas mesquinhas da competitividade universitária, sua irresponsabilidade social e política disfarçada de neutralidade acadêmica e autonomia (HEIDEGGER apud BURNS; RAYMENT-PICKARD 2000, p. 11-12). ${ }^{15}$

É possível pensar em uma oposição entre a história como uma iniciativa pessoal e a história como um conhecimento socialmente relevante, útil para resolver os problemas atuais (ZINN 1990, p. XI). Discutiremos as responsabilidades e oportunidades do historiador dedicado a essa última tarefa: veremos como essa mudança pode gerar uma história mais consciente de sua pertinência ao presente e partícipe do processo de abertura do futuro.

A história não é um curso estabelecido que avança em direção a um futuro previsível. A consciência de que o homem sempre se encontrou preso no momento presente, como estamos hoje, desperta-nos para o fato de que o seu futuro depende em grande parte de fatores que não são controláveis. Devemos abandonar a crença de que a causalidade é linear, de que o passado pode ser conhecido objetivamente e de que o futuro pode ser previsto. O futuro para o qual caminhamos nasce do presente em que estamos e possui raízes no passado vivido, mas uma boa dose desse futuro (um dos muitos possíveis) pertencerá ao improvável, ao desconhecido e ao surpreendente. Edgar Morin inclui essa historicidade em sua formulação sistemática de um "pensamento complexo", destacando sua capacidade de modificar o passado: "há sempre um jogo retroativo entre presente e passado no qual não apenas o passado contribui para o conhecimento do presente, o que é evidente, mas também as experiências desse presente contribuem para o conhecimento do passado e, por isso, o transformam" (MORIN 1981, p. 304). ${ }^{16}$

Modificamos o passado pela interpretação seletiva. Uma reação semelhante ocorre entre presente e futuro: um modifica o outro, multiplicando as variáveis nesse jogo de dados do presente.

O pensador francês é categórico ao afirmar que temos de abandonar o esquema clássico:

passado $\longrightarrow$ presente $\longrightarrow$ futuro

\footnotetext{
${ }_{15}$ No original: "[...] collectively conspiring [...], to pretend that it is self-evidently justifiable for 'professional' historians to be paid to indulge in self-indulgent antiquarianism or the petty intrigues of competitive careerism, their social and political irresponsibility masquerading as academic neutrality of autonomy".

16 No original: "[...] hay siempre un juego retroactivo entre presente y pasado en el que no solamente el pasado contribuye al conocimiento del presente, lo que es evidente, sino también en que las experiencias del presente contribuyen al conocimiento del pasado, y por eso mismo lo transforman".
} 
Pelo que ele chama de "concepção complexa" da historicidade:

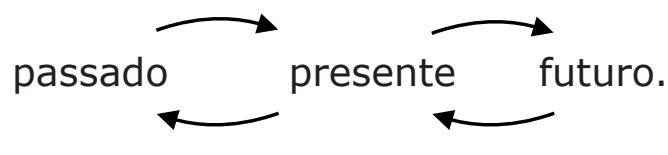

Essa compreensão da historicidade humana apresenta a estrutura do tempo em uma constante relação intrínseca, de modo que, para compreender um momento, temos necessariamente de passar pela análise de seus homólogos. Passado, presente e futuro são interdependentes, estão subordinados uns aos outros. Seria possível adicionar ao diagrama de Morin que futuro e passado estão também interconectados, pois sabemos que esse último certamente será modificado no futuro. Aí reside a contingência do conhecimento histórico.

A consciência de que sempre estivemos nessa situação contingente, movendo-nos no mesmo sentido, desperta a necessidade de um conhecimento do passado que exceda os limites da história atual. Na historicidade complexa de Morin, o passado é chamado a incidir diretamente no despertar da consciência do presente, o que nos remete à teoria helleriana: o passado é sempre constituído por presentes-passados. Isso nos prepara para compreender as descontinuidades, possibilitando ao presente uma reabertura da ideia de futuro. Com uma história que promova o diálogo intercultural e um futuro diverso - aberto à possibilidade de fazer do passado e da memória algo diferente (SOUTHGATE 1996) -, mantemos viva a perspectiva de uma renovação da esperança orientada ao porvir.

Uma noção não teleológica da nossa viagem pelo tempo posiciona o ser humano, bem como os problemas do tempo presente, no centro da história. Um olhar para o que aconteceu é capaz de reverter a relação temporal, mostrando como o passado pode ser usado para realizar uma transformação ética e responsável do presente ao futuro, auxiliando na reabertura do debate sobre o futuro. De fato, uma história "aberta" enfraquece o poder vigente, questiona seus pressupostos de continuidade e retira suas máscaras legitimadoras.

O movimento que tratamos de nomear consiste numa tomada de consciência dos historiadores daquilo que realmente estão fazendo ao transformar o passado em história. Eles têm a opção de reforçar as bases do existente ou a de abrir as pluralidades do que poderia ser - todo historiador usa o passado para moldar o mundo à sua volta, a diferença reside em fazê-lo de forma deliberada ou inconscientemente. O equilíbrio vem da visão centrada nos objetivos que a história vem a servir, e nisso teria pouco a acrescentar à formulação do historiador americano Howard Zinn, que afirma que a historiografia deve estar a serviço da "paz, igualdade racial, segurança econômica, liberdade de expressão, eliminação da guerra, pobreza, ódio racial e nacional, restrições do governo à liberdade individual e [deve] fomentar um espírito de cooperação e preocupação na geração que está crescendo" (ZINN 1990, p. 10; Cf. TODOROV 2002, p. 164). ${ }^{17}$

17 No original: "The university and its scholars [...] should unashamedly declare that their interest is in 
Uma história que nos estimula e desmistifica o presente, que abre a perspectiva mostrando que as coisas já foram e podem ser diferentes, tirando-nos da letargia e expondo a ideologia que se estende por nossa cultura, é preferível à manutenção do mundo atual, uma história que apenas incrementa nossa satisfação com o dado, naturalizando-o: "[o historiador] deve saber como pode participar dessa atividade libertadora e se sua participação implica necessariamente a destruição da própria história" (WHITE 1994, p. 52).

Ciente de seu trabalho político, o historiador será, então, livre para criar significados para a ação presente, dando uso a sua capacidade de pensar o tempo para criar conexões entre passado, presente e futuro.

\section{Crise da historicidade}

Nietzsche é crítico em relação ao regime de historicidade de seus contemporâneos do final do século XIX, acusando-os de carregar muito conhecimento do passado de modo a impedi-los criar o futuro e viver seu presente. Questionando o estatuto do pensamento científico, globalizante, descritivo e objetivo, afirma que o histórico e o a-histórico, memória e esquecimento, devem coexistir em uma vida saudável (NIETZSCHE 1980). Essa é a fórmula que permitiria que o passado fosse revisitado para alimentar o presente, deixando de ser um fardo para a vida. A história deixaria de ser uma lembrança constante da grandeza esmagadora do passado, para nos encorajar a fazer as coisas no presente: seria uma história memento vivere [lembre-se de viver] em vez de memento mori [lembre-se de que morrerá].

Com a queda do Muro de Berlim, o "fim das ideologias" e a dissolução da esperança, o ano de 1989 marca o movimento do pêndulo, o início de um novo regime de historicidade particular à nossa contemporaneidade: sinalizando o fim da experiência histórica que começou no Sattelzeit, passa a ter preeminência a categoria do presente, visto como único horizonte possível. Se havíamos então passado de um modelo baseado no passado a uma historicidade estabelecida no futuro, agora estamos em um regime de historicidade em que o centro de gravidade se desloca do futuro para o presente. "Vivemos em um presente fechado em si mesmo," afirma Hartog (HARTOG 2009; Cf. HUYSSEN 2002). ${ }^{18}$ Ao perguntar-nos se o modelo de historicidade de nossos contemporâneos - no século XXI - se equipara ao observado pelo pensador alemão em seu tempo, vemos que algo mudou. A doença da qual padecemos hoje tem um teor diferente, o peso do passado deu origem a um excesso de presente.

Nesta época do aqui e agora, marcada pela novidade perpétua, o futuro tornou-se imprevisível, diminuindo nossa capacidade de prever o repetível. Nestas circunstâncias, o horizonte de expectativas se aproxima do presente, ameaçando-o, enquanto o espaço da experiência ocupa maior preponderância no mesmo presente - na forma de revivalismos ou ampla discussão política sobre a memória histórica, por exemplo. O fenômeno que vivemos é o de um "'passado 
que não quer passar': um passado que habita o presente, ou melhor, que o assedia, sem tomar distância, como um fantasma" (RICOEUR 1999, p. 41). ${ }^{19}$

Essa adesão do ocorrido ao presente é uma marca da nossa modernidade atual, de um capitalismo globalizado que assimila o conteúdo do nosso passado, transformando toda a realidade de tempos pretéritos em produtos, numa manifestação do que Benjamin chamou de "tempo vazio homogêneo do capitalismo" (HUYSSEN 1995, p. 6). ${ }^{20} \mathrm{Hoje}$, o "passado vende melhor que o futuro" (HUYSSEN 2002, p. 12) a ponto de se tornar uma obsessão contemporânea, na forma de uma completa museificação do mundo. ${ }^{21}$

Todas essas características observáveis no mundo de hoje sugerem uma crise de historicidade, uma transformação da estrutura moderna da temporalidade que se encontra ainda em curso. Ao considerar o papel desempenhado pelo historiador na sociedade, é importante observar o surgimento dessa nova temporalidade híbrida.

\section{Conclusões}

Vivemos um momento adequado para questionar as possibilidades que as novas abordagens sobre historicidade humana podem trazer para o campo da historiografia. O presente se encontra alterado: já não vivemos em uma sociedade marcada pela abertura para o novo, o progressus, mas somos uma civilização que parece satisfazer-se continuamente em um presente eterno.

"Queremos viver como nossos pais!" gritam com resignação os cidadãos dos países mais desenvolvidos do mundo em protesto contra o fim do estado de bem-estar social. Esse é um sintoma de que o horizonte de expectativas tem diminuído, até quase desaparecer. O passado tem se transformado no espaço político protagonista - discutido, legislado -, enquanto, a cada dia e indesejavelmente, o futuro nos parece chegar mais cedo.

É possível discordar das advertências de Roger Chartier quanto a que a disciplina histórica se encontra à beira de um precipício (CHARTIER 1998), mas o régime $d$ 'historicité em mutação e a emergência de uma nova estrutura da temporalidade visivelmente desafiam o lugar da historiografia acadêmica e colocam a relevância social dessa disciplina sob escrutínio. Durante a maior parte de seu passado de 200 anos, a história acadêmica em grande parte aceitou o papel de uma disciplina legitimadora, fazendo pouco para nos ajudar a ver o que poderia ser feito para mudar a ordem atual, quais as possíveis alternativas.

O que tentamos delinear é um possível movimento: de uma leitura do passado que promove resignação, rancor, guerra e tabus - uma história orientada para a manutenção do que há - em direção a uma historicidade equilibrada que promova uma leitura do passado cujo objetivo seja fortalecer o presente, libertando-nos para agir a favor de uma época presente futura menos injusta nas relações entre povos e nações. Para isso, buscamos delinear uma historiografia

\footnotetext{
${ }_{19}$ No original: "'pasado que no quiere pasar': un pasado que habita el presente o, mejor dicho, que lo asedia sin tomar distancia, como un fantasma".

${ }^{20}$ No original: "what Benjamin called the homogenous empty time of the capitalist present".

${ }^{21}$ No original: "[...] el pasado vende mejor que el futuro".
} 
que não crie um mal-entendido no presente, uma história crítica, consciente de sua marca e uso, atenta aos privilégios reivindicados em seu nome por alguns grupos, por exemplo.

A escrita da história não pode ser concebida independentemente de sua posição no entrelaçamento temporal da vida, não pode ser concebida fora do espaço de experiência e do horizonte de expectativas de um agente humano. A historiografia é um conhecimento possível exclusivamente no presente após a sobrevivência de objetos (que evocam o passado do qual provêm). O presente, lugar de confluência de experiências e expectativas, está em constante movimento, um movimento que o distancia do ocorrido. Pode até mesmo separá-lo dele (história passada vs. presente histórico), criando uma lacuna entre o passado e a atualidade.

Tal presente marca profundamente a consciência histórica, resultado da sensação de orientar-se ao longo do tempo. Aceitar sua contingência é aceitar a incerteza do futuro e a insegurança sobre o passado. É importante que o historiador se aproxime do passado como de um presente passado, demonstrando a relevância desse último para o presente, que, por sua vez, influencia o mesmo passado e cria as bases para o futuro.

O historiador passa a entender-se como um mediador dessa relação com os eventos passados. Ao interpretar e elucidar o passado, é ele quem decide o propósito do trabalho histórico e a forma que deve adotar, reintroduzindo uma perspectiva do tempo e formando uma ponte entre passado, presente e futuro.

A história apresentada a partir da perspectiva de uma época presente futura possui o objetivo de facilitar a liberação do imenso fardo que o passado pode representar, permitindo uma abertura em direção a um futuro melhor. Agora que conhecemos a função da máscara da objetividade, podemos ser claros sobre nossas motivações: queremos um futuro mais sustentável, justo e equitativo para toda a população mundial. Queremos restabelecer o equilíbrio entre o homem e seu habitat, queremos um mundo sem violência ou pobreza. Queremos que o conhecimento seja acessível a todos e todas.

Tal renovação da historiografia nos apresentaria uma disciplina plenamente consciente de sua força e localização temporal - em um presente aberto ao futuro e seus problemas, que indaga o passado, fazendo-lhe perguntas úteis. Essa é uma maneira pela qual podemos tornar a repensar o futuro, fazendo uma história diferente, que não busque criar guerras ou reanimar rancores e que favoreça a paz e a justiça buscando a reconciliação entre pontos de vista aparentemente desconexos por meio de um raciocínio e de explicações baseados numa pluralidade de pontos de vista.

A responsabilidade para com o futuro urge uma história libertadora com um olhar sobre o passado, presente e futuro. Essa seria uma historiografia que poderia nos ajudar a superar os traumas causados por eventos extremos e orientar-nos para o que está por vir. As possibilidades são imensas. 


\section{Referências bibliográficas}

ANKERSMIT, Frank. Historical Representation. Stanford: Stanford University Press, 2001.

A escrita da História: a natureza da representação histórica. Londrina: EDUEL, 2012a.

. Meaning, truth and reference in historical representation. Leuven: Leuven University Press, 2012b.

BURNS, Robert; RAYMENT-PICKARD, Hugh. Philosophies of History: From Enlightenment to Postmodernity. Oxford: Blackwell Publishers, 2000.

CHARTIER, Roger. La Historia o la lectura del tiempo. Traduzido por Margarita Polo. Barcelona: Gedisa, 2007.

CRUZ, Manuel. Acerca de la dificultad de vivir juntos. Barcelona: Gedisa, 2007.

DADDOW, Oliver J. No Philosophy Please, We're Historians. Rethinking History, v. 9, n. 1, p. 105-109, 2005.

DANTO, Arthur C. Analytical Philosophy of History. Cambridge: Cambridge University Press, 1965.

HARTOG, François. Régimes d'Historicité: Présentisme et expériences du temps. Paris: Éditions du Seuil, 2003.

. Un Presente Perpetuo. La Nación, Buenos Aires, 10 out. 2009. Disponível em: http://www.lanacion.com.ar/1183005-un-presenteperpetuo. Acesso em: 05 abr. 2013.

HELLER, Agnes. Teoría de la Historia. Traduzido por Javier Honorato. Cidade do México: Fontamara, 1984.

HUYSSEN, Andreas. Twilight Memories: Marking Time in a Culture of Amnesia. Londres: Routledge, 1995.

- En busca del futuro perdido: cultura y memoria en tiempos de globalización. Traduzido por Silvia Fehrmann. Cidade do México: Fondo de Cultura Económica/Goethe Institut, 2002.

JENKINS, Keith. Rethinking History. Londres: Routledge, 1991.

. On "what is history?": from Carr and Elton to Rorty and White. Londres: Routledge, 1995.

. (ed.) The Postmodern History Reader. Londres: Routledge, 1997.

KOSELLECK, Reinhart. Los estratos del tiempo: estudios sobre la historia. Traduzido por Daniel Innerarity. Barcelona: Ediciones Paidós, 2001.

Futures Past: on the semantics of historical time. Traduzido por Keith Tribe. Nova York: Columbia University Press, 2004.

LIPOVETSKY, Gilles. Los tiempos hipermodernos. Traduzido por Antonio 
Prometeo Moya. Barcelona: Anagrama, 2006.

LOWENTHAL, David. The past is a foreign country. Cambridge: Cambridge University Press, 1985.

MORIN, Edgar. Para Salir del Siglo XX. Traduzido por Jordi Fibla. Barcelona: Kairós, 1981.

NIETZSCHE, Friedrich. On the Advantage and Disadvantage of History for Life. Traduzido por Peter Preuss. Indianapolis: Hackett Publishing Company, 1980.

OAKESHOTT, Michael. On history and other essays. Oxford: Basil Blackwell, 1983.

RICOEUR, Paul. La Lectura del Tiempo Pasado: Historia y Olvido. Traduzido por Gabriel Aranzueque. Madrid: Arrecife, 1999.

- Memory, History, Forgetting. Traduzido por Kathleen Blamey e David Pellauer. Londres: University of Chicago Press, 2005.

SOUTHGATE, Beverly. History: what and why?: ancient, modern, and postmodern perspective. $2^{a}$ edição. Londres: Routledge, 1996.

TODOROV, Tzvetan. Las morales de la historia. Traduzido por Marta Beltrán Alcázar. Barcelona: Paidós, 1993.

. Los Abusos de la Memoria. Traduzido por Miguel Salazar. Barcelona: Paidós, 2000.

Memoria del Mal, Tentación del Bien: indagación sobre el siglo XX. Traduzido por Manuel Serrat Crespo. Barcelona: Ediciones Península, 2002.

TRAVERSO, Enzo. Els usos del passat: història, memòria, política. Traduzido por Gustau Muñoz Veiga. Valencia: Universitat de València, 2006.

WHITE, Hayden. Metahistory: The Historical Imagination in Nineteenth Century Europe. 8a edição. Baltimore: John Hopkins University Press, 1993.

. Trópicos do Discurso: ensaios sobre a crítica da cultura. Traduzido por Mauro W. Barbosa de Almeida. São Paulo: Edusp, 1994.

. The Future of Utopia in History. Historein: a Review of the Past and Other Stories, v. 7, p. 5-19, 2007.

ZINN, Howard. The Politics of History. Chicago: Illini Books, 1990. 